\title{
Morbidity and associated factors of depressive disorder in patients with lung cancer
}

This article was published in the following Dove Press journal:

Cancer Management and Research

\author{
Yu Lee' \\ Pao-Yen Lin' \\ Meng-Chih Lin ${ }^{2}$ \\ Chin-Chou Wang ${ }^{2}$ \\ Hung-I Lu ${ }^{3}$ \\ Yung-Che Chen ${ }^{2}$ \\ Mian-Yoon Chong ${ }^{4}$ \\ Chi-Fa Hung' \\ 'Department of Psychiatry, Kaohsiung \\ Chang Gung Memorial Hospital and \\ Chang Gung University College of \\ Medicine Kaohsiung, Kaohsiung, Taiwan; \\ ${ }^{2}$ Division of Pulmonary and Critical Care \\ Medicine, Department of Internal \\ Medicine, Kaohsiung Chang Gung \\ Memorial Hospital and Chang Gung \\ University College of Medicine \\ Kaohsiung, Kaohsiung, Taiwan; \\ ${ }^{3}$ Department of Cardiothoracic Vascular \\ Surgery, Kaohsiung Chang Gung \\ Memorial Hospital and Chang Gung \\ University College of Medicine \\ Kaohsiung, Kaohsiung, Taiwan; ${ }^{4}$ Chang \\ Gung Memorial Hospital, Chiayi, and \\ Chang Gung University School of \\ Medicine, Kaohsiung, Taiwan
}

Correspondence: Chi-Fa Hung

Department of Psychiatry, Kaohsiung

Chang Gung Memorial Hospital, 123 Ta-Pi

Road, Niao-Sung District, Kaohsiung City

833, Taiwan

Tel $+886773|7| 23$ ext. 6316

Fax +88677326817

Email chifa@cgmh.org.tw
Objective: The aim of this study was to assess morbidity and associated factors in patients with lung cancer (LC).

Methods: This study used a cross-sectional design with consecutive sampling. Study subjects were recruited from the LC outpatient clinic and inpatient ward in a medical center from March 2016 to February 2018. Patients with LC were enrolled and assessed using the Mini International Neuropsychiatric Interview, Hamilton Depression Rating Scale, Hamilton Anxiety Rating Scale, Brief Fatigue Inventory, Numeric Pain Rating Scale, and the List of Threatening Experiences Questionnaire.

Results: One hundred and four patients were included in the study. The most prevalent psychiatric disorder was depressive disorder (25.0\%), followed by adjustment disorder $(17.3 \%)$, alcohol use disorder (3.8\%), and insomnia disorder (3.8\%). Fifty percent of patients had a psychiatric diagnosis. Using logistic regression analysis, it was found that severity of fatigue $(\mathrm{OR}=1.77 ; 95 \% \mathrm{CI}, 1.03-3.03 ; p<0.05)$, severity of stressor $(\mathrm{OR}=14.14 ; 95 \% \mathrm{CI}, 2.49$ $80.20 ; p<0.05)$, and severity of anxiety $(\mathrm{OR}=3.75 ; 95 \% \mathrm{CI}, 1.87-7.54 ; p<0.001)$ were three significant associated factors. Patient health problems, death of a close family member or friend, and major financial crisis were the three most common stressors among our cancer patients.

Conclusion: Use of a standardized structured interview for early diagnosis and treatment of cancer patients with depressive disorder is crucial and might increase their quality of life.

Keywords: depression, morbidity, associated factors, lung cancer

\section{Introduction}

Lung cancer (LC) is the leading cause of cancer mortality around the world. ${ }^{1}$ In the United States, LC had the second highest incidence of all cancers; official data reported a total of 83,550 males and 70,500 females that died of LC in the US in $2018 .^{2}$ The overall 5-year survival rate of LC patients is consistently low due to late-stage detection. ${ }^{3}$ Early LC detection has become an important public health issue for mortality reduction.

Outcome of cancer treatment should focus not only on mortality, morbidity, or long-term survival but also on a concern for the mental health care of cancer patients. Previous studies have shown that mental health condition affects patient's quality of life, include well-being and ill-being; control, autonomy, and choice; selfperception; belonging; activity; and hope and hopelessness. ${ }^{4}$ Mental health, besides its impact on the quality of life, furthermore shows relevant associations with the course of disease, eg, cancer, and even mortality.,6

LC is known to be associated with an increased risk of depressive disorder. ${ }^{7}$ Previous studies of LC patients showed high rates of clinically significant 
depressive disorder shortly after diagnosis $(21-44 \%)^{8}$ and after treatment completion (29-44\%). ${ }^{9,10}$ For example, Hopwood and Stephens found that the prevalence of depression, self-rated by the Hospital Anxiety and Depression Scale, was 43\% among 352 small cell LC patients and $21 \%$ among 366 patients with non-small cell LC. ${ }^{8}$ Massie found that the prevalence of depression in patients with LC in prior studies ranged from $11 \%$ to $44 \%{ }^{11,12}$ It should be noted that prior studies designed to detect depression prevalence among LC patients used self-rated questionnaires mostly, instead of structured interviews by clinicians, and this might have yielded false-positive results. ${ }^{13}$ Because higher rates of depression were estimated when using patient self-reported questionnaires, where overrating might be seen in most items of somatic symptoms particularly patients suffering from physical illness. ${ }^{14}$ It is important to use structured diagnostic interview by a senior psychiatrist, although timeconsuming, to accurately detect psychiatric diagnosis of depression in cancer patients.

Literature review found that the risk factors for depressive disorder in patients with LC included cancer stage, ${ }^{15,16}$ health behaviors such as alcohol intake and smoking, ${ }^{15,17}$ physical symptoms such as pain or fatigue, ${ }^{15,18}$ and personal characteristics such as age, ${ }^{19}$ sex (male),${ }^{20}$ employment status, ${ }^{21}$ and lower educational status. ${ }^{22}$

Fatigue is the most common persistent and distressing symptom that patients complain about after the successful treatment of cancer. ${ }^{23}$ Patients with LC have a higher prevalence of cancer-related fatigue, which leads to more functional impairment than among other cancer patients. ${ }^{24}$ Previous studies have shown that fatigue is associated with depression in cancer patients. ${ }^{25}$ However, few studies have reported fatigue as an associated factor of depression in patients with LC.

In addition to the aforementioned associated factors of depression in LC patients, stress, anxiety symptom, and resilience are also common psychosocial problems among cancer patients. ${ }^{14,26-30}$ Resilience is defined as abilities and traits of individuals, which help patients to quickly overcome adversity and stress, and regain the normal psycho-emotional state. ${ }^{29,30}$ Prior studies have demonstrated that resilience, positive adaptation to protect from psychological distress, is not only associated with quality of life but also a predictor of quality of life in cancer patients. ${ }^{31}$ Studies indicated that high level of anxiety predicted worse quality of life concurrently and longitudinally in breast cancer patients. ${ }^{32,33}$ Again, few studies have focused on the association among stressful life events, anxiety symptom, resilience, and depressive disorder in patients with LC.

Based on the earlier literature review, the hypotheses of this study are 1) The most prevalent psychiatric disorder is depressive disorder; 2) The prevalence of depressive disorder is approximately $20 \%$; 3 ) The associated factors of depressive disorder are a late cancer stage, fatigue, pain, severe stress, severe anxiety, and resilience issues.

We aimed to evaluate the psychiatric morbidity in patients with LC using a structured diagnostic interview as gold standard by psychiatrist and investigated the associated factors of depressive disorders.

\section{Methods}

\section{Participants}

This study used a cross-sectional design with consecutive sampling. Participants were recruited from the chest and cardiovascular surgery outpatient/inpatient department at a tertiary hospital from March 2016 to February 2018. This hospital has 2754 beds and provides yearly services to 5000 cancer patients per year in southern Taiwan. Inclusion criteria were as follows: (1) patients newly diagnosed LC; (2) patients with the ability to understand the study procedure and complete the questionnaires. Exclusion criteria were as follows: (1) patients with a diagnosis of schizophrenia, schizoaffective disorder, or bipolar I disorder; (2) patients with dementia or severe cognitive impairment; (3) patients whose depression was caused by another general medical condition (eg, thyroid disease) or induced by substances; (4) patients who are too weak to complete the questionnaire or clinical interview.

\section{Assessments}

\section{Brief Fatigue Inventory (BFI)}

The Brief Fatigue Inventory was developed for the rapid assessment of fatigue severity for use in both clinical screening and clinical trials and is especially widely applied among patients with cancer. ${ }^{34}$ The BFI is also used to assess the severity of fatigue experienced by cancer patients interfered with their ability to function during the previous $24 \mathrm{hrs}$. The BFI, consisting of severity and interference subscales, can be used as a self-report questionnaire or as an interview by research staff. The Taiwanese version of the Brief Fatigue Inventory (BFI-T) was validated in a sample of 439 Taiwanese patients with 
multiple cancer diagnoses, and the results showed satisfactory reliability and validity. ${ }^{35}$

\section{Numeric Pain Rating Scale (NPRS)}

The Numeric Pain Rating Scale (NPRS) is a unidimensional measure of pain intensity in adults, including those with cancer pain. ${ }^{36}$ The 11-point numeric scale ranges from " 0 " representing one pain extreme (eg, "no pain") to "10" representing the other pain extreme (eg, "worst pain imaginable"). One study examined the test-retest reliability of the NPRS and found good stability for the NPRS scoring for worst pain $(\mathrm{r}=0.93)$ and average pain $(\mathrm{r}=0.78)$ during about a 2 -day period. ${ }^{36}$ Satisfactory validity has been observed in patients with cancer. ${ }^{37}$

\section{The Questionnaire Version of the List of Threatening Experiences (LTE-Q)}

The Questionnaire Version of the List of Threatening Experiences (LTE-Q) by Brugha et al has overcome the difficulties of clinical application by means of its brevity and was adapted for use in psychiatric studies focusing on social support and coping, and in situations in which resources do not allow for the use of extensive interview measures of stress. ${ }^{38,39}$ In a study of 50 psychiatric patients and informants, the LTE-Q was shown to have satisfactory test-retest reliability and good agreement with informants. $^{39}$ The LTE-Q lists not only serious illness, injury, and death of close others or other major losses but also many life events with little or no threat. ${ }^{38}$

\section{Connor-Davidson Resilience Scale (CD-RISC)}

Resilience is used to measure the ability to cope with stress. The original Connor-Davidson Resilience scale (CD-RISC) was a self-reported 25-item scale with scores ranging between 0 and 4 per item. ${ }^{40}$ Higher score means greater resilience. An abridged version of the CD-RISC comprising 10 items was developed on the basis of factor analysis, providing a rapid and brief method to quantify resilience. The assessment time is approximately 3 mins. ${ }^{40}$ Good reliability and validity were confirmed among different populations and diseases. ${ }^{40,41}$

\section{Hamilton Depression Rating Scale (HAM-D)}

The Hamilton Depression Rating Scale (HAM-D) was designed to be researcher-administered and is used to probe mood, feelings of guilt, suicide ideation, insomnia, agitation or retardation, anxiety, weight loss, and somatic symptoms. $^{42}$ The HAM-D has been widely applied to assess the severity of depression, though it has been criticized for overemphasis on neurovegetative symptoms. The reliability and validity of the Chinese version of the 17-item HAM-D have been verified, and it can be used in clinical and research settings. ${ }^{43}$

\section{Hamilton Anxiety Rating Scale (HAM-A)}

The Hamilton Anxiety Rating Scale (HAM-A) is one of the first and is the most widely used rating scale to measure the severity of perceived anxiety symptoms. ${ }^{44}$

The HAM-A, with 14 symptom-defined elements, is a clinician-based questionnaire and includes both psychological and somatic symptoms. Each item is scored using a basic numeric range of 0 (not present) to 4 (severe). ${ }^{44}$ One study examined the HAM-A's reliability and validity, and concluded that its inter-rater reliability, one-week test-retest reliability, and concurrent validity were satisfactory. ${ }^{45}$

Mini International Neuropsychiatric Interview (MINI) The MINI is a short, structured clinical interview and was designed to help make accurate psychiatric diagnoses, especially of depressive disorders and anxiety disorders, based on the DSM-IV or ICD-10. ${ }^{46}$ It has good sensitivity and specificity and can be administered by trained nonphysicians. The validity and reliability of the MINI have been assessed with the Structured Clinical Interview for DSM-IIIR Patients (SCID-P) with satisfactory results. ${ }^{47}$ Although no formal study on the validity of the Taiwan version of the MINI has been conducted, it has been widely used in several earthquake studies. The assessment time is approximately $15-20$ mins.

\section{Procedures}

Ethical approval was obtained from the human research ethics committee of Chang Gung Memorial Hospital. Study procedures were as follows: (1) Newly diagnosed patients visiting our collaborative care clinic or admitted to our ward were invited consecutively to take part in this study. Once our research assistant received referral from outpatient clinic or wards from in-charge doctors or case manager, our research assistant went to the above settings to contact patients. After explaining the study procedure and aims, those who agreed to sign an informed consent form were enrolled in the study. (2) A senior psychiatrist (Dr Y. Lee) made the psychiatric diagnoses using the MINI and mood condition assessments using the HAMD and HAM-A. (3) The BFI, NPRS, LTE-Q, CD-RISC, and clinical and demographic data were collected by a trained research assistant. 


\section{Statistical analyses}

Descriptive and inferential statistics were analyzed using SPSS for Windows V. 12.0. Descriptive statistics (chisquare and independent sample $t$-tests) were performed first to test the difference in demographic data and clinical characteristics between subjects with and without depressive disorder. Logistic regression was used to test the factors associated with depressive disorder.

\section{Results}

Initially, 118 patients were invited to take part in this study; 14 patients did not complete the study due to resistance or refusal. Data collection was completed for 104 patients, for a response rate of $88.1 \%$.

In all, $53.9 \%(n=56)$ of the 104 subjects that successfully completed the study were males. The average age of the subjects was $61.3( \pm 10.3)$ years. Their mean education level was $9.9( \pm 4.2)$ years, $81.7 \%$ were married, and $25.0 \%$ were currently employed. Eighty-four percent of the patients had advanced (stage III and IV) disease, and $48 \%$ had comorbidity of one or more physical illnesses. The average waist-to-hip ratio was $0.91( \pm 0.07)$ (Table 1$)$. The most common treatment modality was chemotherapy (50.5\%), followed by a targeted drug (40.4\%) (Table 1).

The most common psychiatric diagnoses in LC patients at the pretreatment phase were depressive disorder (25.0\%), followed by adjustment disorder (17.3\%), alcohol use disorder (3.8\%), and insomnia disorder (3.8\%). Fifty percent of patients had a psychiatric diagnosis (Table 2).

In the univariate analyses of 104 cancer patients, factors significantly associated with depressive disorders included a self-harm history (15.4 vs $1.3 ; \mathrm{t}=8.47$, $p<0.001)$, severity of stressor $(1.42$ vs $0.51 ; \mathrm{t}=4.93$, $p<0.001$ ), severity of resilience ( 26.58 vs $31.60 ; \mathrm{t}=-3.43$, $p<0.05$ ), severity of fatigue ( 3.79 vs $2.46 ; \mathrm{t}=2.49, p<0.05$ ), and severity of anxiety (11.27 vs $5.06 ; \mathrm{t}=10.33, p<0.001)$ (Table 1). When the above significant factors were analyzed relative to depressive disorders using the stepwise forward model of logistic regression, it was found that severity of fatigue $(\mathrm{OR}=1.77 ; 95 \% \mathrm{CI}, 1.03-3.03$; $p<0.05$ ), severity of stressor ( $\mathrm{OR}=14.14 ; 95 \% \mathrm{CI}, 2.49$ $80.20 ; p<0.05)$, and severity of anxiety $(\mathrm{OR}=3.75 ; 95 \%$ CI, 1.87-7.54; $p<0.001)$ were three significant associated factors (Table 3 ).

Among the subset of the LTE-Q, the most serious stressor was the patient's health problem, followed by death of a close family member or friend, close relative with a serious illness, and major financial crisis. When comparing depressives and non-depressives in terms of life stressors on the LTE-Q, it was found that patient's health problem, close relative with a serious illness, death of a close relative or family member, separation due to marital difficulties, and interpersonal serious problems were more significantly stressful in depressive patients than in non-depressive patients (Table 4).

\section{Discussion}

Our study suggested a high level of psychiatric morbidity (50\%) among LC patients at the initial pre-treatment period. The most prevalent psychiatric diagnosis in this study was depressive disorder, followed by adjustment disorder. Depressive disorder was the most common psychiatric diagnosis. This result is compatible with that of previous studies, in which LC patients were commonly comorbid with depression, at a range of $11-44 \% .{ }^{11}$ A study from Thailand examined $104 \mathrm{LC}$ patients using the MINI interview; 15 (14.4\%) of them were diagnosed as having major depressive disorder (MDD). ${ }^{48}$ In our study, $9.6 \%$ of the patients were diagnosed as having MDD and $15.4 \%$ of the patients had depressive disorder not otherwise specified. These 2 studies from Asia suggest that patients with LC are quite often comorbid with depressive disorder. In addition, depression morbidity in both studies was within the range of 14.4-25\%, which was lower than in some studies of LC patients with a depression morbidity up to $44 \%{ }^{11}$ The possible explanation is that both studies used a structured diagnostic interview by a clinician, which would render a lower morbidity rate than the self-rated questionnaires used in other clinical studies. Delayed diagnosisrelated biological vulnerability and psychological impact can partially explain the high prevalence of depression in LC patients. Disadvantaged social determinants of LC patients, eg, lower socioeconomic status leads to increased smoking or experiences more physical symptoms, also contribute high morbidity of depression in patients with LC. ${ }^{49}$

The prevalence of anxiety disorders in our study (1.1\%) was far lower than expected among LC patients. This result is consistent with the study from China, in which there were fewer patients with anxiety disorder than patients with depressive disorder (6.5\% vs $66.7 \%) .{ }^{50}$ Even though these cancer patients presented mild-to-moderate anxiety symptoms after being informed of the disease, they were not serious enough to be diagnosed specifically as anxiety disorder. Only one patient fulfilled the diagnostic criteria of post-traumatic stress disorder. Our included patients were in 
Table I Demographic and clinical characteristics of depressives and non-depressives among lung cancer patients

\begin{tabular}{|c|c|c|c|c|c|}
\hline Characteristics & $\begin{array}{l}\text { Patients with non-depression } N \\
(\%), N=78\end{array}$ & $\begin{array}{l}\text { Patients with depression } N \\
(\%), N=26\end{array}$ & $\begin{array}{l}\text { Total } N(\%) \\
N=104\end{array}$ & $\begin{array}{l}\mathrm{X} 2 / T- \\
\text { test }\end{array}$ & $P$ \\
\hline $\begin{array}{l}\text { Gender } \\
\text { Male } \\
\text { Female }\end{array}$ & $\begin{array}{l}42(53.85) \\
36(46.15)\end{array}$ & $\begin{array}{l}14(53.85) \\
12(46.15)\end{array}$ & $\begin{array}{l}56(53.85) \\
48(46.15)\end{array}$ & 0 & 1.00 \\
\hline Age, years mean (SD) & $61.71( \pm 10.18)$ & $59.92( \pm 10.73)$ & $61.26( \pm 10.30)$ & -0.76 & 0.45 \\
\hline $\begin{array}{l}\text { Marital status } \\
\text { Unmarried } \\
\text { Married }\end{array}$ & $\begin{array}{l}16(20.51) \\
62(79.49)\end{array}$ & $\begin{array}{l}3(I I .54) \\
23(88.46)\end{array}$ & $\begin{array}{l}19(18.27) \\
85(81.73)\end{array}$ & 1.05 & 0.31 \\
\hline $\begin{array}{l}\text { Education, years } \\
\text { mean (SD) }\end{array}$ & $9.76( \pm 4.39)$ & $10.38( \pm 3.60)$ & $9.91( \pm 4.20)$ & 0.66 & 0.51 \\
\hline Unemployed & $56(71.79)$ & $17(65.38)$ & $73(70.19)$ & 0.38 & 0.54 \\
\hline \multicolumn{6}{|l|}{ Substance used } \\
\hline Alcohol & $21(26.90)$ & $6(23.10)$ & $27(26.00)$ & 0.15 & 0.70 \\
\hline Tobacco & $32(41.00)$ & II (42.30) & $43(41.30)$ & 0.01 & 0.91 \\
\hline Betel-nut & $13(16.70)$ & $4(15.38)$ & $17(16.30)$ & 0.02 & 0.88 \\
\hline Self-harm history & $\mathrm{I}(\mathrm{I} .30)$ & $4(\mid 5.38)$ & $5(4.80)$ & 8.47 & 0.004 \\
\hline Other diseases & $40(51.28)$ & $10(38.46)$ & $50(48.08)$ & 1.28 & 0.26 \\
\hline BMI (SD) & $22.96( \pm 3.33)$ & $23.83( \pm 3.70)$ & $23.17( \pm 3.43)$ & 1.11 & 0.27 \\
\hline Systolic pressure & $131.32( \pm \mid 8.85)$ & $130.04( \pm 13.45)$ & $131.00( \pm 17.60)$ & -0.31 & 0.76 \\
\hline Diastolic pressure & $76.78( \pm \mid 1.55)$ & $72.63( \pm 7.13)$ & $75.74( \pm 10.74)$ & -1.66 & 0.10 \\
\hline Waist-to-hip ratio & $0.90( \pm 0.07)$ & $0.92( \pm 0.06)$ & $0.91( \pm 0.07)$ & 1.39 & 0.17 \\
\hline \multicolumn{6}{|l|}{ Treatment } \\
\hline Operation & $20(25.64)$ & $3(11.54)$ & $23(22.12)$ & & \\
\hline Chemotherapy & $36(46.15)$ & $15(57.69)$ & $51(49.04)$ & & \\
\hline Radiotherapy & $8(10.26)$ & $4(15.38)$ & $12(11.54)$ & & \\
\hline Targeted drug & $32(41.03)$ & $10(38.46)$ & $42(40.38)$ & & \\
\hline Stage & & & & 1.90 & 0.17 \\
\hline Early & $15(19.23)$ & $2(7.70)$ & $17(16.35)$ & & \\
\hline Advanced & $63(80.77)$ & $24(92.30)$ & $87(83.65)$ & & \\
\hline NPRS, mean (range) & $1.78(0-10)$ & $1.88(0-10)$ & $1.8 I(0-10)$ & 0.21 & 0.84 \\
\hline LTE-Q, mean (range) & $0.5 \mathrm{I}(0-4)$ & $1.42(0-6)$ & $0.74(0-6)$ & 3.77 & 0.001 \\
\hline CDRISC, mean (SD) & $31.60(6.36)$ & $26.58(6.8 I)$ & $30.35( \pm 6.80)$ & -3.43 & 0.001 \\
\hline BFI-S, mean (SD) & $2.49( \pm 2.26)$ & $3.79( \pm 2.13)$ & $2.82( \pm 2.29)$ & 2.58 & 0.01 \\
\hline BFI-I, mean (range) & $1.09(0-7.7)$ & $2.49(0-9.3)$ & I.44(0-9.3) & 3.60 & $<0.001$ \\
\hline HAMD, mean (SD) & $4.91( \pm 2.93)$ & $13.35( \pm 3.27)$ & $7.02( \pm 4.74)$ & 12.35 & $<0.001$ \\
\hline HAMA, mean (SD) & $5.06( \pm 2.74)$ & $11.27( \pm 2.38)$ & $6.62( \pm 3.38)$ & 10.33 & $<0.001$ \\
\hline
\end{tabular}

Abbreviations: NPRS, Numeric Pain Rating Scale; LTEQ, Questionnaire Version of the List of Threatening Experiences; CORISC, Connor-Davidson Resilience Scale; BFI-S, Brief Fatigue Inventory Severity Subscale; BFI-I, Brief Fatigue Inventory Interference Subscale; HAMD, Hamilton Depression Rating Scale, HAMA, Hamilton Anxiety Rating Scale; Depressive disorder NOS, depressive disorder not otherwise specified.

the pretreatment phase and were at the stage of dealing with loss process. That might be the reason why the psychiatric diagnosis of our patients was more likely to be adjustment disorder than anxiety disorders. ${ }^{51}$ 
Table 2 Psychiatric diagnoses of lung cancer patients

\begin{tabular}{|c|c|c|c|}
\hline Category and diagnosis & $\begin{array}{l}\text { Patients with non-depression } \\
\mathbf{N}(\%), \mathbf{N}=78\end{array}$ & $\begin{array}{l}\text { Patients with depression } \\
\mathbf{N}(\%), \mathbf{N}=\mathbf{2 6}\end{array}$ & Total $N(\%) ~ N=104$ \\
\hline Depressive disorders & 0 & $26(100.00)$ & $26(25.00)$ \\
\hline Major depressive disorder & 0 & $10(38.50)$ & $10(9.60)$ \\
\hline Depressive disorder NOS & 0 & $16(61.50)$ & $16(15.40)$ \\
\hline Adjustment disorder & $18(23.10)$ & 0 & $18(17.30)$ \\
\hline Alcohol use disorder & $3(3.80)$ & $\mathrm{I}(3.80)$ & $4(3.80)$ \\
\hline Post-traumatic stress disorder & 0 & $\mathrm{I}(3.80)$ & $\mathrm{I}(1.00)$ \\
\hline Insomnia disorder & $4(5.10)$ & 0 & $4(3.80)$ \\
\hline REM sleep behavior disorder & 0 & 0 & 0 \\
\hline No psychiatric disorder & $52(66.70)$ & 0 & $52(50.00)$ \\
\hline
\end{tabular}

Abbreviations: REM sleep behavior disorder, rapid eye movement sleep behavior disorder; NOS, not otherwise specified.

Table 3 Associated factors for depressive disorder at the pretreatment phase among patients with lung cancer: logistic regression analysis

\begin{tabular}{|l|l|l|l|l|l|l|}
\hline Item & $\boldsymbol{\beta}$ & SE & Walds & Odds ratio & CI & $\boldsymbol{P}$ \\
\hline BFI-I & 2.65 & 0.28 & 4.25 & 1.77 & $1.03-3.03$ & 0.04 \\
LTEQ & 1.18 & 0.89 & 8.95 & 14.14 & $2.49-80.20$ & 0.003 \\
HAMA & 1.32 & 0.36 & 13.85 & 3.75 & $1.87-7.54$ & $<0.001$ \\
\hline
\end{tabular}

Abbreviations: BFI-I, Brief Fatigue Inventory Interference Subscale; LTEQ, Questionnaire Version of the List of Threatening Experiences; HAMA, Hamilton Anxiety Rating Scale.

There were three significant associated factors of depressive disorder among our cancer patients: severity of fatigue, severity of stressor, and severity of anxiety. Severity of stressor is the most robust associated factor of depressive disorder in our study. It is not an uncommon notion that a stressful life event is usually correlated with depressive disorder. ${ }^{52}$ However, only a few studies have detected a relationship between depression and stressor in cancer patients. One of the studies explored life events and depressive symptoms after breast cancer surgery. The result suggested that cancer-related traumatic stress and the life event, major financial difficulty, along with a tendency toward negativity, may heighten depressive symptoms. ${ }^{53}$ Although studies that elucidate the stressor is one of the depressive disorder's associated factors among cancer patients are still scant, the abovementioned study can partially support our finding that a stressful life event is associated with depressive disorder in LC cancer patients. It is noteworthy that a patient's health problem, the death of a close family member or friend, close relative with a serious illness, and a major financial crisis were the four most common stressors among our cancer patients. Very few psycho-oncological studies have explored the context of stressors before. More studies are needed in the future to confirm this finding.
We found that depressive cancer patients have a nearly fourfold severity of anxiety compared to non-depressive cancer patients. The majority of patients with MDD suffer from comorbid anxiety disorder or subsyndromal anxiety symptoms. ${ }^{54}$ Due to its importance in the clinical course of MDD, the Diagnostic and Statistical Manual of Mental Disorders, Fifth Edition (DSM-5) adopted an anxiety specifier in MDD. ${ }^{55}$ This comorbidity phenomenon might support our finding that anxiety symptom is an associated factor of depressive disorder. A possible explanation for why depressive cancer patients more commonly have anxiety symptoms is that cancer patients have to face a survival crisis, treatment adverse effects, being abandoned, loss of self-control, etc. ${ }^{56}$ To date, several studies investigated depression and anxiety are comorbid in the cancer patients. ${ }^{56,57}$ However, very few studies have detected anxiety symptoms as an associated factor in cancer patients comorbid with depressive disorder. More studies are needed to examine this finding.

Fatigue was one of the significant associated factors of depression in our study. Cancer-related fatigue is a pervasive and distressing problem in patients with cancer. Depression was significantly associated with fatigue in previous studies, with correlation coefficients ranging from 0.16 to $0.84 .^{25}$ A longitudinal study from the USA 
Table 4 Comparison of severity of LTE-Q between depressives and non-depressives among lung cancer patients

\begin{tabular}{|c|c|c|c|c|c|}
\hline Item & $\begin{array}{l}\text { Patients with non- } \\
\text { depression } N(\%) \text {, } \\
(n=78)\end{array}$ & $\begin{array}{l}\text { Patients with } \\
\text { depression N(\%), } \\
(n=26)\end{array}$ & $\begin{array}{l}\text { Total N } \\
(\%), \\
(n=104)\end{array}$ & $\mathbf{t}$ & $p$ \\
\hline $\begin{array}{l}\text { I. You yourself suffered a serious illness, injury or an } \\
\text { assault. }\end{array}$ & $0.24( \pm 0.43)$ & $0.50( \pm 0.51)$ & $0.31( \pm 0.46)$ & 2.50 & 0.01 \\
\hline $\begin{array}{l}\text { 2. A serious illness, injury or assault happened to a close } \\
\text { relative. }\end{array}$ & $0.04( \pm 0.19)$ & $0.15( \pm 0.37)$ & $0.07( \pm 0.25)$ & 2.06 & 0.04 \\
\hline 3. Your parent, child or spouse died. & $0.03( \pm 0.16)$ & 0 & $0.02( \pm 0.14)$ & 0.82 & 0.42 \\
\hline $\begin{array}{l}\text { 4. A close family friend or another relative (aunt, cousin, } \\
\text { or grandparent) died. }\end{array}$ & $0.05( \pm 0.22)$ & $0.19( \pm 0.40)$ & $0.09( \pm 0.28)$ & 2.25 & 0.03 \\
\hline 5. You had a separation due to marital difficulties. & 0 & $0.08( \pm 0.27)$ & $0.02( \pm 0.14)$ & 2.53 & 0.01 \\
\hline 6. You broke off a steady relationship. & 0 & 0 & 0 & 0 & 0 \\
\hline $\begin{array}{l}\text { 7. You had a serious problem with a close friend, } \\
\text { neighbor or relative. }\end{array}$ & 0 & $0.08( \pm 0.27)$ & $0.02( \pm 0.14)$ & 2.53 & 0.01 \\
\hline $\begin{array}{l}\text { 8. You became unemployed or you were seeking work } \\
\text { unsuccessfully for more than one month. }\end{array}$ & $0.03( \pm 0.16)$ & $0.04( \pm 0.20)$ & $0.03( \pm 0.17)$ & 0.34 & 0.74 \\
\hline 9. You were sacked from your job. & 0 & 0 & 0 & 0 & 0 \\
\hline 10. You had a major financial crisis. & $0.05( \pm 0.22)$ & $0.12( \pm 0.33)$ & $0.07( \pm 0.25)$ & 1.13 & 0.26 \\
\hline $\begin{array}{l}\text { II. You had problem with the police and a court } \\
\text { appearance. }\end{array}$ & $0.04( \pm 0.19)$ & $0.04( \pm 0.20)$ & $0.04( \pm 0.19)$ & 0.00 & 1.00 \\
\hline 12. Something you valued was lost or stolen. & $0.01( \pm 0.11)$ & $0.04( \pm 0.20)$ & $0.02( \pm 0.14)$ & 0.82 & 0.42 \\
\hline
\end{tabular}

Abbreviation: LTE-Q, Questionnaire Version of the List of Threatening Experiences.

evaluated the directionality of the association between depression and cancer-related fatigue. Although they found that depressive symptoms and fatigue were strongly correlated (baseline correlation of latent variables $=0.71$ ), their findings did not support the directionality of the relationship between depressive symptoms and fatigue. ${ }^{58}$ Maneeton et al reported that fatigue severity was a significant predictor of severity of depressive disorder in LC patients, which supported our finding. ${ }^{48}$ Fatigue and depression are common symptoms in cancer patients. Evidence from recent research suggests that both symptoms are distinct entities in cancer patients. ${ }^{58}$ More largescale longitudinal studies are needed to examine whether fatigue is a risk factor for depressive disorder in cancer patients.

Our findings reveal that a past history of self-harm and resilience were both associated with depressive disorder. Prior studies showed that patients with high severity of suicide ideation were associated with severity of depression and with having depressive disorder. ${ }^{59}$ Although very few papers mention that patients with a self-harm history are at risk of developing depressive disorder, it can be speculated that patients with a self-harm history are vulnerable to stressors and tend to develop depressive disorder. LC patients have a high morbidity of depression and a high risk of suicide. ${ }^{60,61}$ To date, few studies have found that LC patients with a self-harm history are at risk of developing depression. Large sample-sized studies should be conducted to test this hypothesis, with the aim of preventing the co-occurrence of depression and suicide in LC patients.

The CD-RISC was used in the present study to evaluate LC patients' resilience. We found that depressed patients had significantly lower CD-RISC scores than non-depressed patients. This CD-RISC result is partially supported by the findings of a previous study, which suggested that the high levels of depression among LC patients were related to poor resilience. ${ }^{30}$ Resilience indicates the ability of patients to protect or recover their mental health despite the existence of objective 
difficulties, eg, cancer. ${ }^{29}$ Our data indicated that lower resilience was not only related to depression severity but also associated with depressive disorder in LC patients. More studies are needed to confirm this finding.

The strengths of this study are the high response rate and the use of a structured clinical interview by one psychiatrist. However, our study has several limitations. First, consecutive sampling opened the study to the possibility of sampling bias. Nevertheless, the over $80 \%$ response rate of the newly diagnosed cancer patients compromised this limitation. Second, the limited sample numbers of patients with LC that failed to test accurate associated factors of depressive disorder. Larger-scale studies of LC patients should be performed in the future to overcome the aforementioned limitation. Third, our samples were from a general hospital and may not be representative of the general population. Last, this was a cross-sectional study, which did not allow for an investigation of the patients' depressive disorder throughout the course of the disease. Therefore, further follow-up studies should be conducted to help understand depressive disorder morbidity and the associated risk factors.

To conclude, our study has three clinical implications: 1) The most prevalent psychiatric disorder was depressive disorder, followed by adjustment disorder, alcohol use disorder, and insomnia disorder. 2) Fatigue, severity of stressor, and severity of anxiety were significant associated factors for depressive disorder in LC patients; 3) Patient health problems, death of a close family member or friend, and major financial crisis were the most common stressors among our cancer patients. Finally, the use of a standardized structured interview is important for early diagnosis of depressive disorder in LC patients. Once the diagnosis is made, proper management needs to be provided to improve patient quality of life. Large-scale follow-up studies should be conducted to confirm morbidity and risk factors of depression in patients with LC. We also should provide necessary education for LC patients and clinician to understand cancer patient might comorbid with depression and to have early detection and treatment of depression.

\section{Ethics statement}

All procedures performed in studies involving human participants were in accordance with the Declaration of Helsinki (1964) and its later amendments or comparable ethical standards.

\section{Abbreviations}

LC, lung cancer; BFI, Brief Fatigue Inventory; NPRS, Numeric Pain Rating Scale; LTE-Q, Questionnaire Version of the List of Threatening Experiences; CD-RISC, ConnorDavidson Resilience Scale; HAM-D, Hamilton Depression Rating Scale; HAM-A, Hamilton Anxiety Rating Scale; MINI, Mini International Neuropsychiatric Interview; SCIDP, Structured Clinical Interview for DSM-IIIR Patients Version; DSM-IV, Diagnostic and Statistical Manual of Mental Disorders, Fourth Edition; ICD-10, The International Statistical Classification of Diseases and Related Health Problems, 10th Revision; OR, odds ratio; CI, confidence interval; MDD, major depressive disorder; DSM-5, Diagnostic and Statistical Manual of Mental Disorders, Fifth Edition.

\section{Acknowledgments}

This study was supported by a grant from Kaohsiung Chang Gung Memorial Hospital, Taiwan (CMRPG8E1381).

\section{Disclosure}

The authors report no conflicts of interest in this work.

\section{References}

1. Torre LA, Bray F, Siegel RL, Ferlay J, Lortet-Tieulent J, Jemal A. Global cancer statistics, 2012. CA Cancer J Clin. 2015;65(2):87-108. doi:10.3322/caac. 21294

2. Siegel RL, Miller KD, Jemal A. Cancer statistics, 2018. CA Cancer J Clin. 2018;68(1):7-30. doi:10.3322/caac.21442

3. Marcus MW, Raji OY, Field JK. Lung cancer screening: identifying the high risk cohort. $J$ Thorac Dis. 2015;7:S156-S162.

4. Connell J, Brazier J, O'Cathain A, Lloyd-Jones M, Paisley S. Quality of life of people with mental health problems: a synthesis of qualitative research. Health Qual Life Outcomes. 2012;10:138. doi:10.1186/1477-7525-10-138

5. Schulze T, Maercker A, Horn AB. Mental health and multimorbidity: psychosocial adjustment as an important process for quality of life. Gerontology. 2014;60(3):249-254. doi:10.1159/000358559

6. Musuuza JS, Sherman ME, Knudsen KJ, Sweeney HA, Tyler CV, Koroukian SM. Analyzing excess mortality from cancer among individuals with mental illness. Cancer. 2013;119(13):2469-2476. doi:10.1002/cncr.28091

7. Turner NJ, Muers MF, Haward RA, Mulley GP. Psychological distress and concerns of elderly patients treated with palliative radiotherapy for lung cancer. Psycho-Oncology. 2007;16(8):707-713. doi:10.1002/(ISSN)1099-1611

8. Hopwood P, Stephens RJ. Depression in patients with lung cancer: prevalence and risk factors derived from quality-of-life data. J Clin Oncol. 2000;18(4):893-903. doi:10.1200/JCO.2000.18.10.2059

9. Kurtz ME, Kurtz JC, Stommel M, Given CW, Given B. Predictors of depressive symptomatology of geriatric patients with lung cancer-a longitudinal analysis. Psycho-Oncology. 2002;11(1):12-22. doi:10.1002/pon.545

10. Nakaya N, Saito-Nakaya K, Akizuki N, et al. Depression and survival in patients with non-small cell lung cancer after curative resection: a preliminary study. Cancer Sci. 2006;97(3):199-205. doi:10.1111/ j.1349-7006.2006.00160.x 
11. Massie MJ. Prevalence of depression in patients with cancer. J Natl Cancer Inst Monogr. 2004;32:57-71. doi:10.1093/jncimonographs/ $\operatorname{lgh} 014$

12. Sullivan DR, Forsberg CW, Ganzini L, et al. Longitudinal changes in depression symptoms and survival among patients with lung cancer: a national cohort assessment. J Clin Oncol. 2016;34(33):3984-3991. doi:10.1200/JCO.2016.66.8459

13. Wu YS, Lin PY, Chien CY, et al. Anxiety and depression in patients with head and neck cancer: 6-month follow-up study. Neuropsychiatr Dis Treat. 2016;12:1029-1036. doi:10.2147/NDT.S103203

14. Akechi T, Ietsugu T, Sukigara M, et al. Symptom indicator of severity of depression in cancer patients: a comparison of the DSM-IV criteria with alternative diagnostic criteria. Gen Hosp Psychiatry. 2009;31 (3):225-232. doi:10.1016/j.genhosppsych.2008.12.004

15. Akechi T, Okamura H, Nishiwaki Y, Uchitomi Y. Psychiatric disorders and associated and predictive factors in patients with unresectable nonsmall cell lung carcinoma: a longitudinal study. Cancer. 2001;92(10):2609-2622. doi:10.1002/(ISSN)1097-0142

16. Uchitomi Y, Mikami I, Kugaya A, et al. Depression after successful treatment for nonsmall cell lung carcinoma. Cancer. 2000;89 (5):1172-1179. doi:10.1002/1097-0142(20001115)89:10<2068::aidcncr6>3.0.co; $2-\mathrm{z}$

17. Schnoll RA, Malstrom M, James C, et al. Correlates of tobacco use among smokers and recent quitters diagnosed with cancer. Patient Educ Couns. 2002;46(2):137-145. doi:10.1016/S0738-3991(01) 00157-4

18. Okuyama T, Tanaka K, Akechi T, et al. Fatigue in ambulatory patients with advanced lung cancer: prevalence, correlated factors, and screening. J Pain Symptom Manage. 2001;22(1):554-564. doi:10.1016/S0885-3924(01)00305-0

19. Lo C, Zimmermann C, Rydall A, et al. Longitudinal study of depressive symptoms in patients with metastatic gastrointestinal and lung cancer. J Clin Oncol. 2010;28(18):3084-3089. doi:10.1200/ JCO.2009.26.9712

20. Shi Y, Gu F, Hou LL, Hu YQ. Self-reported depression among patients with non-small cell lung cancer. Thorac Cancer. 2015;6 (3):334-337. doi:10.1111/1759-7714.12179

21. Agarwal M, Hamilton JB, Moore CE, Crandell JL. Predictors of depression among older African American cancer patients. Cancer Nurs. 2010;33(2):156-163. doi:10.1097/NCC.0b013e3181bdef76

22. Uchitomi Y, Mikami I, Nagai K, Nishiwaki Y, Akechi T, Okamura H. Depression and psychological distress in patients during the year after curative resection of non-small-cell lung cancer. J Clin Oncol. 2003;21(1):69-77. doi:10.1200/JCO.2003.12.139

23. Gupta D, Lis CG, Grutsch JF. The relationship between cancerrelated fatigue and patient satisfaction with quality of life in cancer. J Pain Symptom Manage. 2007;34(1):40-47. doi:10.1016/ j.jpainsymman.2006.10.012

24. Forlenza MJ, Hall P, Lichtenstein P, Evengard B, Sullivan PF Epidemiology of cancer-related fatigue in the Swedish twin registry. Cancer. 2005;104(9):2022-2031. doi:10.1002/cncr.21400

25. Brown LF, Kroenke K. Cancer-related fatigue and its associations with depression and anxiety: a systematic review. Psychosomatics. 2009;50(5):440-447. doi:10.1016/S0033-3182(09)70835-7

26. Seib C, Porter-Steele J, Ng SK, et al. Life stress and symptoms of anxiety and depression in women after cancer: the mediating effect of stress appraisal and coping. Psychooncology. 2018;27(7):1787-1794. doi:10.1002/pon.4849

27. Todd BL, Moskowitz MC, Ottati A, Feuerstein M. Stressors, stress response, and cancer recurrence: a systematic review. Cancer Nurs. 2014;37(2):114-125. doi:10.1097/NCC.0b013e318289a6e2

28. Arrieta O, Angulo LP, Núñez-Valencia C, et al. Association of depression and anxiety on quality of life, treatment adherence, and prognosis in patients with advanced non-small cell lung cancer. Ann Surg Oncol. 2013;20(6):1941-1948. doi:10.1245/s10434-012-2793-5
29. Ristevska-Dimitrovska G, Stefanovski P, Smichkoska S, Raleva M, Dejanova B. Depression and resilience in breast cancer patients. Open Access Maced J Med Sci. 2015;3(4):661-665. doi:10.3889/ oamjms.2015.119

30. Hu T, Xiao J, Peng J, Kuang X, He B. Relationship between resilience, social support as well as anxiety/depression of lung cancer patients: a cross-sectional observation study. J Cancer Res Ther. 2018;14(1):72-77. doi:10.4103/jcrt.JCRT_849_17

31. Li MY, Yang YL, Liu L, Wang L. Effects of social support, hope and resilience on quality of life among Chinese bladder cancer patients: a cross-sectional study. Health Qual Life Outcomes. 2016;14:73. doi:10.1186/s12955-016-0481-z

32. You J, Lu Q, Zvolensky MJ, Meng Z, Garcia K, Cohen L. Anxietyand health-related quality of life among patients with breast cancer: a cross-cultural comparison of China and the United States. J Glob Oncol. 2018;(4):1-9. doi:10.1200/JGO.2016.008763

33. So WKW, Marsh G, Ling WM, et al. Anxiety, depression and quality of life among Chinese breast cancer patients during adjuvant therapy. Eur J Oncol Nurs. 2010;14(1):17-22. doi:10.1016/j. ejon.2009.07.005

34. Mendoza T, Wang XS, Cleeland CS, et al. The rapid assessment of fatigue severity in cancer patients: use of the Brief Fatigue Inventory. Cancer. 1999;85(5):1186-1196. doi:10.1002/(SICI)1097-0142 (19990301)85:5<1186::AID-CNCR24>3.0.CO;2-N

35. Lin CC, Chang AP, Chen ML, Cleeland CS, Mendoza TR, Wang XS. Validation of the Taiwanese Version of the Brief Fatigue Inventory. $J$ Pain Symptom Manage. 2006;32(1):52-59. doi:10.1016/j.jpainsymman.2005.12.019

36. Jensen MP. The validity and reliability of pain measures in adults with cancer. J Pain. 2003;4(1):2-21.

37. Paice JA, Cohen FL. Validity of a verbally administered numeric rating scale to measure cancer pain intensity. Cancer Nurs. 1997;20 (2):88-93.

38. Brugha TS, Cragg D. The List of Threatening Experiences: the reliability and validity of a brief life events questionnaire. Acta Psychiatr Scand. 1990;82(1):77-81.

39. Brugha T, Bebbington P, Tennant C, Hurry J. The List of Threatening Experiences: a subset of 12 life event categories with considerable long-term contextual threat. Psychol Med. 1985;15(1):189-194.

40. Connor KM, Davidson JR. Development of a new resilience scale: the Connor-Davidson Resilience Scale (CD-RISC). Depress Anxiety. 2003;18(2):76-82. doi:10.1002/da.10113

41. Ye ZJ, Qiu HZ, Li PF, et al. Validation and application of the Chinese version of the 10-item Connor-Davidson Resilience Scale (CD-RISC10) among parents of children with cancer diagnosis. Eur J Oncol Nurs. 2017;27:36-44. doi:10.1016/j.ejon.2017.01.004

42. Hamilton M. A rating scale for depression. J Neurol Neurosurg Psychiatry. 1960;23:56-62. doi:10.1136/jnnp.23.1.56

43. Zheng YP, Zhao JP, Phillips M, et al. Validity and reliability of the Chinese Hamilton Depression Rating Scale. Br $J$ Psychiatry. 1988;152:660-664. doi:10.1192/bjp.152.5.660

44. Hamilton M. The assessment of anxiety states by rating. $\mathrm{Br} \mathrm{J} \mathrm{Med}$ Psychol. 1959;32(1):50-55.

45. Maier W, Buller R, Philipp M, Heuser I. The Hamilton Anxiety Scale: reliability, validity and sensitivity to change in anxiety and depressive disorders. Affect Disord. 1988;14(1):61-68. doi:10.1016/ 0165-0327(88)90072-9

46. Sheehan DV, Lecrubier Y, Sheehan KH, et al. The Mini-International Neuropsychiatric Interview (M.I.N.I.): the development and validation of a structured diagnostic psychiatric interview for DSM-IV and ICD-10. J Clin Psychiatry. 1998;59(Suppl 20):22-33.

47. Sheehan DV, Lecrubier Y, Sheehan KH. The validity of the Mini International Neuropsychiatric Interview (MINI) according to the SCID-P and its reliability. Eur Psychiatry. 1997;12(5):232-241. doi:10.1016/S0924-9338(97)83297-X 
48. Maneeton B, Maneeton N, Reungyos J, Intaprasert S, Leelarphat S, Thongprasert S. Prevalence and relationship between major depressive disorder and lung cancer: a cross-sectional study. Onco Targets Ther. 2014;7:815-821. doi:10.2147/OTT.S60000

49. Fagundes C, Desiree Jones D, Vichaya E, Lu C, Cleeland CS. Socioeconomic status is associated with depressive severity among patients with advanced non-small cell lung cancer: treatment setting and minority status do not make a difference. J Thorac Oncol. 2014;9 (10):1459-1463. doi:10.1097/JTO.0000000000000284

50. Hong JS, Tian J. Prevalence of anxiety and depression and their risk factors in Chinese cancer patients. Support Care Cancer. 2014;22 (2):453-459. doi:10.1007/s00520-013-1997-y

51. Lee Y, Chien CY, Lin PY, et al. Psychiatric morbidity, pain, anxiety and depression in patients with head and neck cancer and lung cancer. Int J Head Neck Sci. 2017;1(3):191-198. doi:10.6696/ IJHNS.2017.0103.06

52. Finlay-Jones R, Brown GW. Types of stressful life event and the onset of anxiety and depressive disorders. Psychol Med. 1981;11 (4):803-815.

53. Golden-Kreutz DM, Andersen BL. Depressive symptoms after breast cancer surgery: relationships with global, cancer-related, and life event stress. Psychooncology. 2004;13(3):211-220. doi:10.1002/ pon. 736

54. Zimmerman M, McDermut W, Mattia JI. Frequency of anxiety disorders in psychiatric outpatients with major depressive disorder. Am J Psychiatry. 2000;157(8):1337-1340. doi:10.1176/appi.ajp.157.8.1337
55. American Psychiatric Association. Diagnostic and Statistical Manual of Mental Disorders. 5th ed. Arlington (VA): American Psychiatric Association; 2013.

56. Brown CG, Brodsky J, Cataldo JK. Lung cancer stigma, anxiety, depression and quality of life. J Psychosoc Oncol. 2014;32(1):5973. doi: $10.1080 / 07347332.2013 .855963$

57. Rutkowski J, Szymanik M, Blok M, Kozaka J, Zaucha R. Prospective evaluation of anxiety, depression and quality of life in medically inoperable early stage non-small cell lung cancer patients treated with stereotactic ablative radiotherapy. Rep Pract Oncol Radiother. 2017;22(3):217-222. doi:10.1016/j.rpor.2017.01.002

58. Brown LF, Rand KL, Bigatti SM, et al. Longitudinal relationships between fatigue and depression in cancer patients with depression and/ or pain. Health Psychol. 2013;32(12):1199-1208. doi:10.1037/a0029773

59. O’Brien G, Holton AR, Hurren K, Watt L, Hassanyeh F. Deliberate self harm-correlates of suicidal intent and severity of depression. Acta Psychiatr Scand. 1987;75(5):474-477.

60. Urban D, Rao A, Bressel M, Neiger D, Solomon B, Mileshkin L. Suicide in lung cancer: who is at risk? Chest. 2013;144(4):12451252. doi:10.1378/chest.12-2986

61. Sullivan DR, Forsberg CW, Golden SE, Ganzini L, Dobscha SK, Slatore CG. Incidence of suicide and association with palliative care among patients with advanced lung cancer. Ann Am Thorac Soc. 2018;15(11):1357-1359. doi:10.1513/AnnalsATS.201805-299RL

\section{Publish your work in this journal}

Cancer Management and Research is an international, peer-reviewed open access journal focusing on cancer research and the optimal use of preventative and integrated treatment interventions to achieve improved outcomes, enhanced survival and quality of life for the cancer patient.
The manuscript management system is completely online and includes a very quick and fair peer-review system, which is all easy to use. Visit http://www.dovepress.com/testimonials.php to read real quotes from published authors. 